\title{
Case Report \\ Osteoporosis-Related Simultaneous Four Joints Fractures and Dislocation after a Seizure: A Case Report
}

\author{
Abdullah S. AlOmran ${ }^{1,2}$ \\ ${ }^{1}$ College of Medicine, King Faisal University, Dammam, Saudi Arabia \\ ${ }^{2}$ College of Medicine, King Fahd University Hospital, P.O. Box 40052, Al-Khobar 31952, Saudi Arabia
}

Correspondence should be addressed to Abdullah S. AlOmran, alomran_a_s@yahoo.com

Received 29 July 2009; Revised 22 November 2009; Accepted 10 January 2010

Academic Editor: Heikki Kröger

Copyright (C) 2010 Abdullah S. AlOmran. This is an open access article distributed under the Creative Commons Attribution License, which permits unrestricted use, distribution, and reproduction in any medium, provided the original work is properly cited.

A case of steroid-induced osteoporosis-related multiple fractures and dislocations are described after a seizure is reported. Patient had two years history of steroid use with no supplement or antiresorptive therapy. There was a delay in the diagnosis which affected an otherwise good outcome in such situations. It is recommended that patients on steroid should be given calcium, vitamin D, and an antiresorptive. Furthermore, a meticulous clinical examination is required in patients who are on steroids and suffer epileptic seizures to rule out skeletal injury.

\section{Introduction}

Prolonged use of corticosteroids cause osteoporosis by both decreasing osteoblastic and increasing osteoclastic activity [1-3]. Skeletal trauma after seizure is well known. However, we are reporting here a case of simultaneous bilateral femoral neck fractures and bilateral humeral neck fractures after one episode of seizure. The patient had two years use of high dose steroid with no antiresorptive therapy. Investigations postinjury documented osteoporosis. This is the first reported simultaneous four axial joints fractures.

\section{Case Report}

A 36 years old Saudi Male was brought to the Emergency Room following a generalized convulsions and loss of consciousness. He was driving a car and felt an acute sharp pain at right shoulder, few seconds later, he developed blurring of vision and he was able to stop the car and lost consciousness for 15-20 minutes. He was observed to have rolling up of the eyes with frothy salivations and trauma to the tongue. The patient complained of severe arthralgia and pain on minimal movement of any joint. On examination he was noted to have petechiae all over his body, no signs of meningeal irritation and there was a lesion over the scapula which was diagnosed as a snake bite. Blood investigations were normal and computerized tomography of the brain was normal. Patient was loaded with phenytoin $25 \mathrm{mg} / \mathrm{Kg}$ body weight. In the ward he developed echymotic lesions on the skin and upper extremities, with recurrent vomiting, distended abdomen, paralytic ileus, and deteriorating renal and liver function tests. In the intensive care unit the patient was treated by antivenom and supportive therapy. At the end of the 7th day the general condition improved and patient started to complain of painful hips and shoulders. On further inquiry, patient gave a history of using $15 \mathrm{mg}$ prednisolone daily for aplastic anemia for two years. No supplement or antiresorptive therapy was given to him. Clinical examination showed that both the shoulder joints were dislocated and any attempt to move the hips and right wrist caused tremendous amount of pain. Radiographs showed that bilateral anterior dislocation of shoulder with bilateral fracture surgical neck, Smith's fracture of the right radius and bilateral fracture of the neck of femur (Garden IV) (Figures 1 and 2). Under general anesthesia both shoulder joints were reduced, fracture necks of femur were fixed with two cannulated screws (Figure 3), Smith's fracture was reduced and plaster of paris application was done. Two weeks 


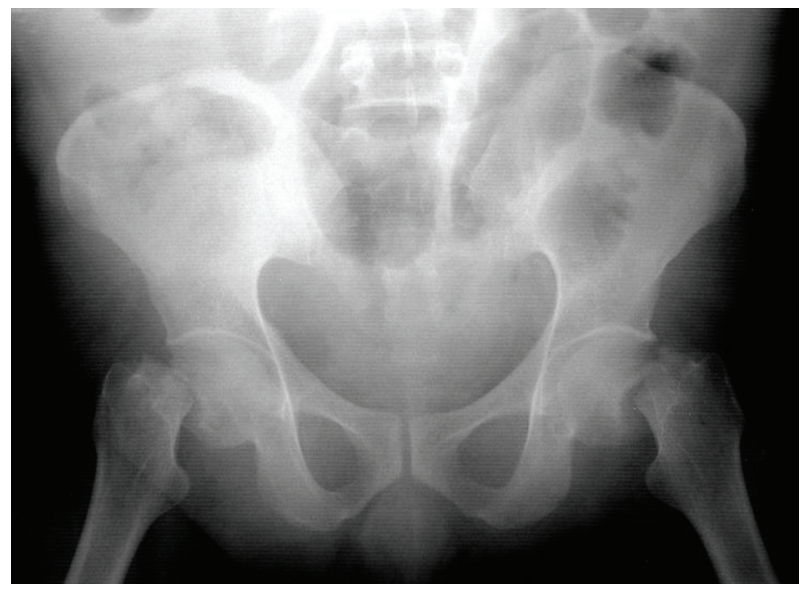

FIgURE 1: Radiograph of the pelvis showing bilateral fracture of neck of femur.

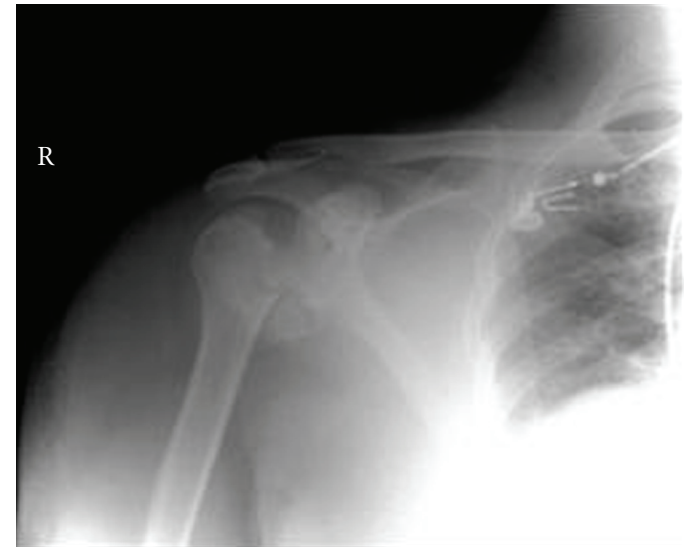

(a)

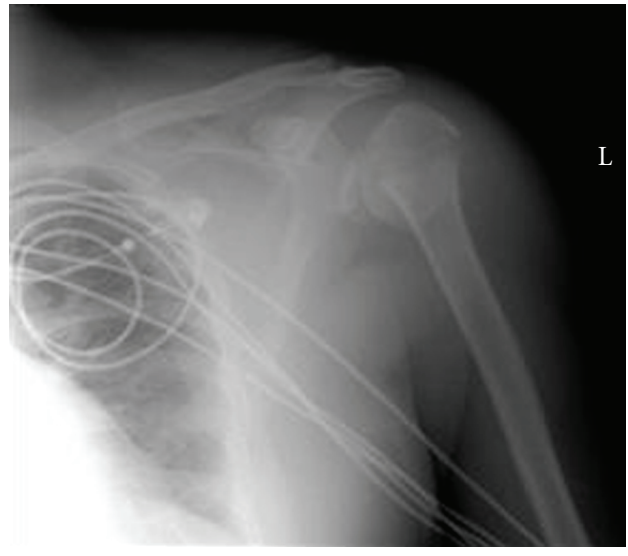

(b)

FigURE 2: X. ray of both shoulders revealing dislocations.

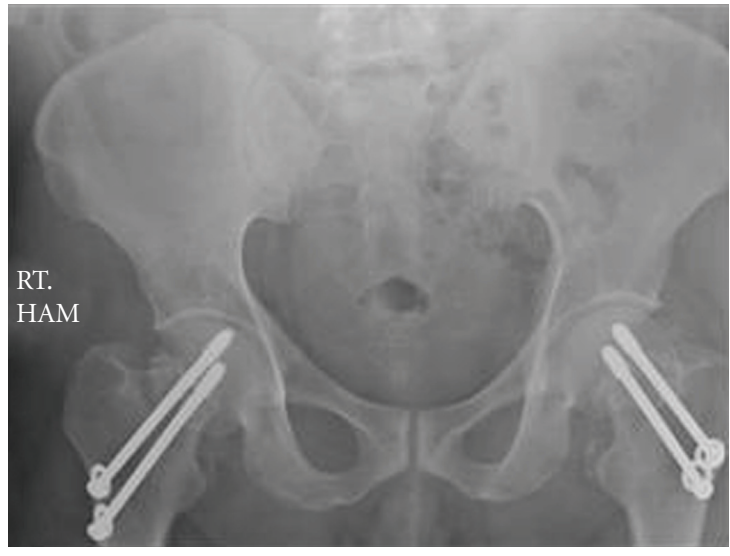

(a)

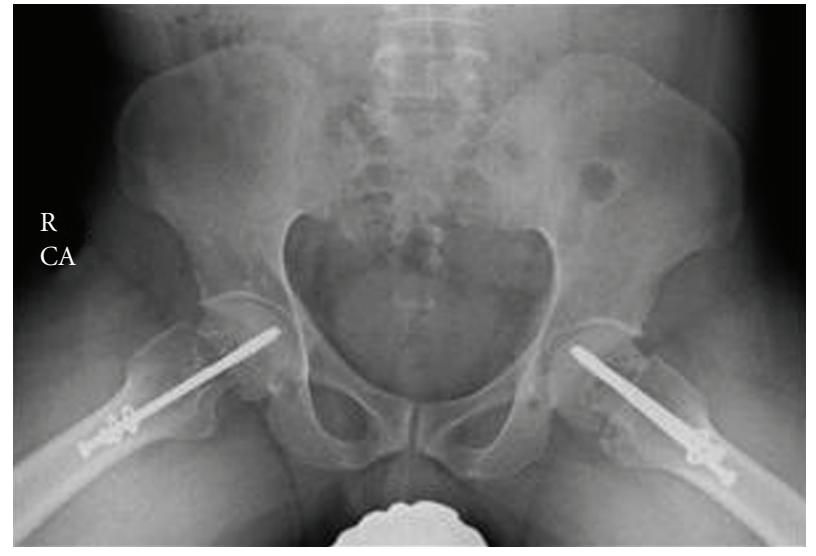

(b)

Figure 3: Postfixation of fracture neck of femurs. 
later, bone mineral density of the spine (Dual Energy X-ray Absorptiometry, DEXA scan) showed severe osteoporosis with $\mathrm{T}$ score of -2.9 . Last follow-up appointment was four years from the incidence and revealed no pain but rather painless limping. Examination showed right hip and left hip had limited range of movements and pain at extreme degree. The range of movements of the shoulder joints were normal.

\section{Comments}

Corticosteroids cause low bone mass by cellular apoptosis causing both decreased osteoblastic and increased osteoclastic activity [1]. It is well established that long-term use of glucocorticoid use increases risk of fractures [2, 3]. De Vries et al. [4] reported that a daily dose of higher or equal to 15 milligrams have a substantial higher risk of fractures but Steinbuch et al. [5] believed that higher dose and longer duration is needed to increase the risk of fractures. The guidelines for prevention of Glucocorticoidinduced osteoporosis has been long proposed [6-9]. Devogelaer et al. [10] reported that supplemental calcium and vitamin $\mathrm{D}$ should be the first-line therapy in patients receiving $\geq 7.5$ milligrams/daily. Compston [11] suggested that bisphosphonates should be the treatment of choice, with supplementation of calcium and vitamin D. more recent studies [12] suggest teriparatide as a replacement of alandronate. our patient was on $15 \mathrm{mg}$ of prednisolone with no supplementation or antiresorptive therapy.

Skeletal trauma due to generalized tonic and clonic seizures is not uncommon. Vertebral fractures [13], femoral neck [14], skull [14], shoulder, and humeral head [15] have been reported. Joshy [16] reported a case of bilateral femoral neck fracture due to an epileptic fit. Our patient sustained bilateral femoral neck fractures, bilateral shoulder surgical neck fracture dislocations and a Smith's fracture. It has been reported that fractures are 2-6 times more common in epileptic patients than the general population [17-19]. This has been blamed on low bone mass which is caused by antiepilepsy drugs [20], but our patient sustained all the injuries during the first known attack of the epileptic fit and had steroid-induced low bone mass.

Bilateral hip fractures are not uncommon and occur due to high energy trauma, and early diagnosis reduces the incidence of permanent disability. Skeletal injuries due to postepileptic fit could be of serious consequences as the diagnosis is often delayed which cause long-term functional disability [21], which in our patient ended in bilateral avascular necrosis of head of femur. Delay in the diagnosis was thought to be due to the fact that patients remain in the intensive care unit, often unconscious and ventilated. Our patient was not ventilated but was complaining of severe arthralgia and difficulty in moving the limbs should have alerted the treating physicians.

Our case demonstrates that when patients are being treated with long-term steroids, need to be treated with antiresorptives otherwise an episode of epileptic fit could lead to major skeletal trauma.

\section{References}

[1] E. Canalis, G. Mazziotti, A. Giustina, and J. P. Bilezikian, "Glucocorticoid-induced osteoporosis: pathophysiology and therapy," Osteoporosis International, vol. 18, no. 10, pp. 13191328, 2007.

[2] N. F. A. Peel, D. J. Moore, N. A. Barrington, D. E. Bax, and R. Eastell, "Risk of vertebral fracture and relationship to bone mineral density in steroid treated rheumatoid arthritis," Annals of the Rheumatic Diseases, vol. 54, pp. 801-806, 1995.

[3] A. Verstraeten and J. Dequeker, "Vertebral and peripheral bone mineral content and fracture incidence in postmenopausal patients with rheumatoid arthritis: effect of low dose corticosteroids," Annals of the Rheumatic Diseases, vol. 45, pp. 852-857, 1986.

[4] F. de Vries, M. Bracke, H. G. M. Leufkens, J.-W. J. Lammers, C. Cooper, and T. P. van Staa, "Fracture risk with intermittent high-dose oral glucocorticoid therapy," Arthritis and Rheumatism, vol. 56, no. 1, pp. 208-214, 2007.

[5] M. Steinbuch, T. E. Youket, and S. Cohen, "Oral glucocorticoid use is associated with an increased risk of fracture," Osteoporosis International, vol. 15, no. 4, pp. 323-328, 2004.

[6] American College of Rheumatology Ad Hoc Committee on Glucocorticod-Induced Osteoporosis, "Recommendation for the prevention and treatment of glucocorticod-induced osteoporosis," Arthritis and Rheumatism, vol. 44, pp. 14961503, 2001.

[7] R. A. Adler and M. C. Hochberg, "Suggested guidelines for evaluation and treatment of glucocorticoid-induced osteoporosis for the department of veterans affairs," Archives of Internal Medicine, vol. 163, pp. 2619-2624, 2003.

[8] National Osteoporosis Society, Guidelines on the Prevention and Management of Corticosteroid-Induced Osteoporosis, NOS, London, UK, 1998.

[9] R. Eastell, D. M. Reid, J. Compston, et al., "A UK Consensus Group on management of glucocorticoid-induced osteoporosis: an update," Journal of Internal Medicine, vol. 244, pp. 271292, 1998.

[10] J.-P. Devogelaer, S. Goemaere, S. Boonen, et al., "Evidencebased guidelines for the prevention and treatment of glucocorticoid-induced osteoporosis: a consensus document of the Belgian Bone club," Osteoporosis International, vol. 17, no. 1, pp. 8-19, 2006.

[11] J. E. Compston, "Emerging consensus on prevention and treatment of glucocorticoid-induced osteoporosis," Current Rheumatology Reports, vol. 9, no. 1, pp. 78-84, 2007.

[12] S. L. Silverman and N. E. Lane, "Glucocorticoid-induced osteoporosis," Current Osteoporosis Reports, vol. 7, no. 1, pp. 23-26, 2009.

[13] D. A. Hepburn, J. M. Steel, and B. M. Frier, "Hypoglycemic convulsions cause serious musculoskeletal injuries in patients with IDDM," Diabetes Care, vol. 12, no. 1, pp. 32-34, 1989.

[14] P. F. Finelli and J. K. Cardi, "Seizure as a cause of fracture," Neurology, vol. 39, pp. 858-860, 1989.

[15] A. Goldman, O. Sherman, A. Price, and J. Minkoff, "Posterior fracture dislocation of the shoulder with biceps tendon interposition," Journal of Trauma, vol. 27, no. 9, pp. 10831086, 1987.

[16] S. Joshy, "Bilateral femoral neck fracture following convulsions: pitfalls in early diagnosis and management," The Internet Journal of Orthopedic Surgery, vol. 2, no. 1, 2004.

[17] P. Vestergaard, S. Tigaran, L. Rejnmark, C. Tigaran, M. Dam, and L. Mosekilde, "Fracture risk is increased in epilepsy," Acta Neurologica Scandinavica, vol. 99, pp. 269-275, 1999. 
[18] P. C. Souverein, D. J. Webb, H. Petri, J. Weil, T. P. Van Staa, and T. Egberts, "Incidence of fractures among epilepsy patients: a population-based retrospective cohort study in the general practice research database," Epilepsia, vol. 46, pp. 304-310, 2005.

[19] R. H. Mattson and B. E. Gidal, "Fractures, epilepsy, and antiepileptic drugs," Epilepsy Behavior, vol. 5, supplement 2, pp. S36-S40, 2004.

[20] R. D. Sheth, B. E. Gidal, and B. P. Hermann, "Pathological fractures in epilepsy," Epilepsy and Behavior, vol. 9, pp. 601605, 2006.

[21] J. S. Blanco, G. Dahir, and K. McCrystal, "Bilateral femoral neck fractures secondary to hypocalcemic seizures in a skeletally immature patient," American Journal of Orthopedics, vol. 3, pp. 187-188, 1999. 


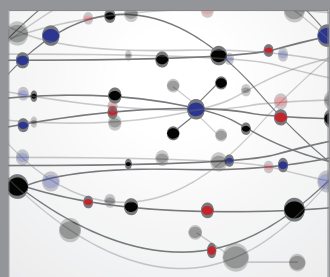

The Scientific World Journal
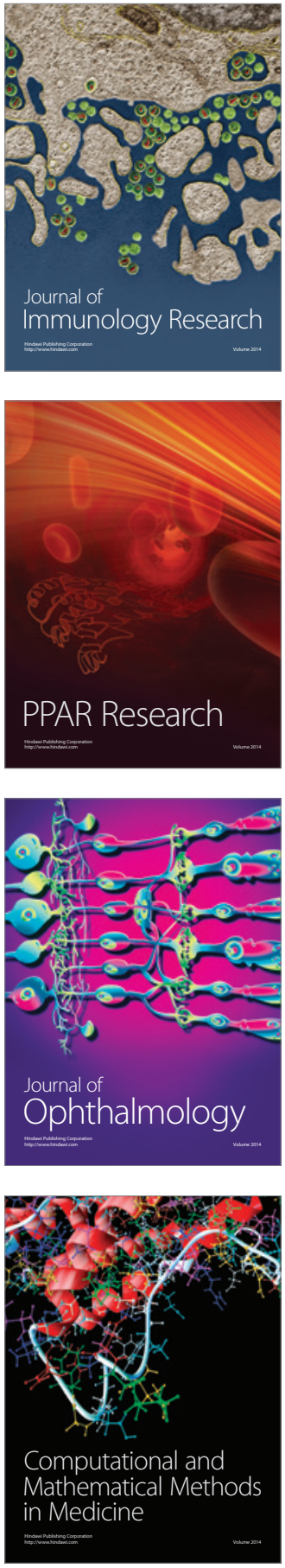

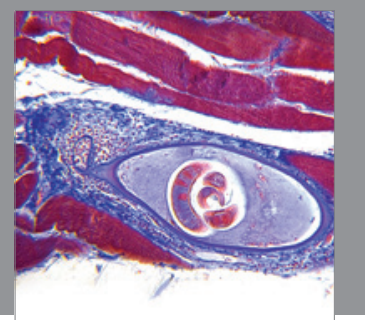

Gastroenterology

Research and Practice
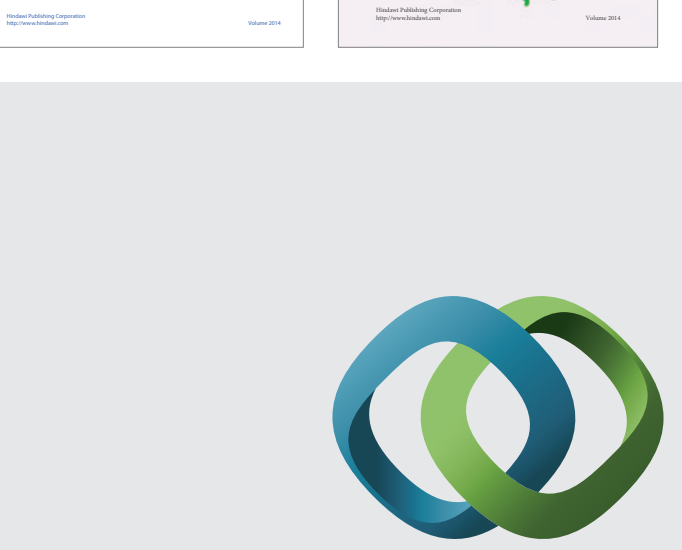

\section{Hindawi}

Submit your manuscripts at

http://www.hindawi.com
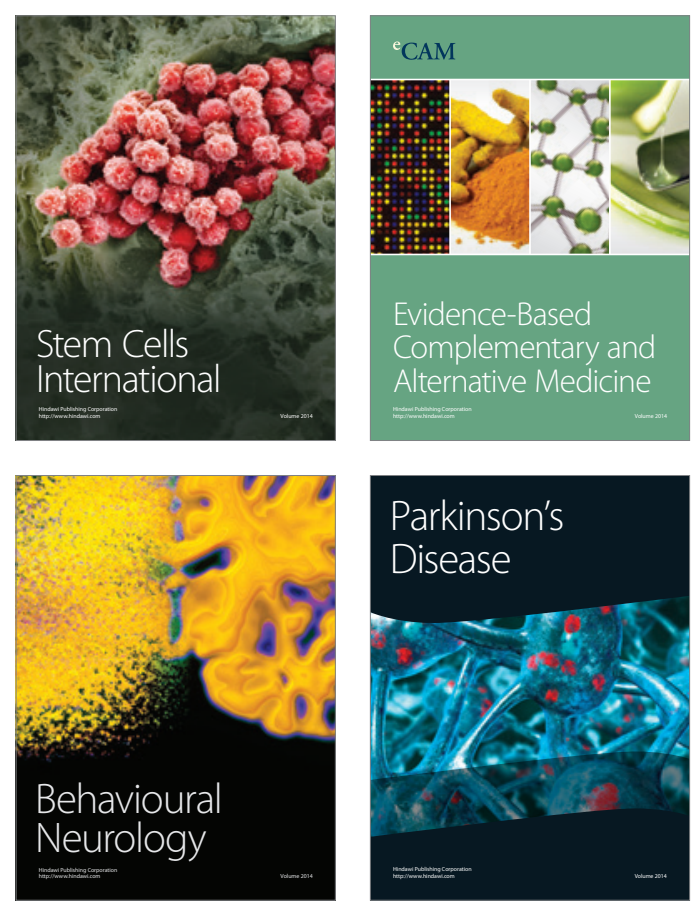

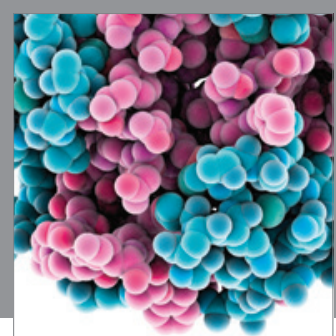

Journal of
Diabetes Research

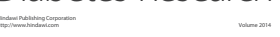

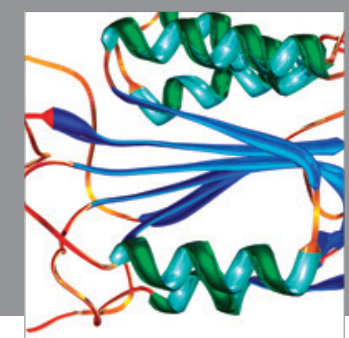

Disease Markers
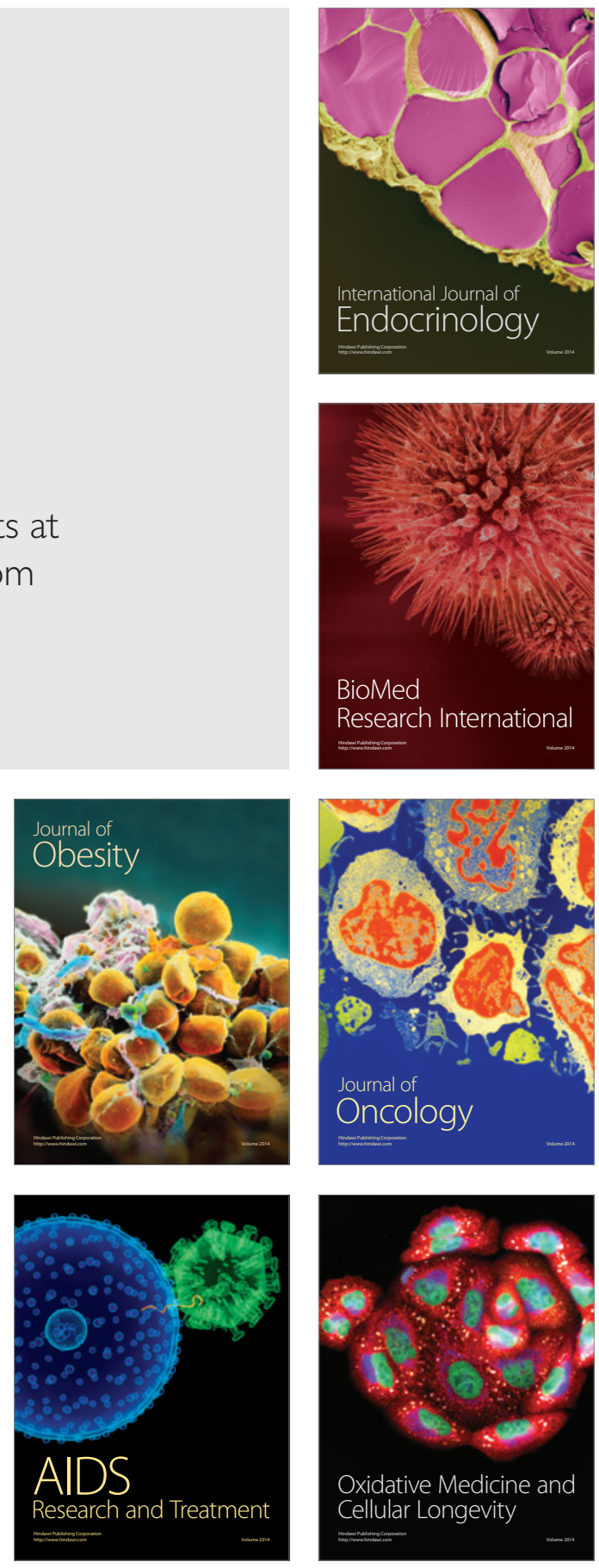